\title{
Prophylactic cranial irradiation in locally advanced non-small cell lung cancer: outcome of recursive partitioning analysis group I patients
}

\author{
Ali Aydin Yavuz*, Erkan Topkan, Cem Onal and Melek Nur Yavuz
}

Address: Baskent University Medical Faculty, Adana Medical and Research Center, Department of Radiation Oncology, Kisla Saglik Yerleskesi, Adana, Turkey

Email: Ali Aydin Yavuz* - ayavuz@baskent-adn.edu.tr; Erkan Topkan - drerkantopkan@yahoo.com; Cem Onal - hcemonal@hotmail.com; Melek Nur Yavuz - myavuz@baskent-adn.edu.tr

* Corresponding author

Published: 4 December 2008

Journal of Experimental \& Clinical Cancer Research 2008, 27:80 doi:10.1 186/1756-9966-27-80

This article is available from: http://www.jeccr.com/content/27///80

(C) 2008 Yavuz et al; licensee BioMed Central Ltd.

This is an Open Access article distributed under the terms of the Creative Commons Attribution License (http://creativecommons.org/licenses/by/2.0), which permits unrestricted use, distribution, and reproduction in any medium, provided the original work is properly cited.
Received: 22 October 2008

Accepted: 4 December 2008

\begin{abstract}
Background: Prophylactic cranial irradiation (PCl) has been demonstrated to reduce or delay the incidence of brain metastases (BM) in locally advanced non-small cell lung carcinoma (LA-NSCLC) patients with various prognostic groups. With this current cohort we planned to evaluate the potential usefulness of prophylactic cranial irradiation ( $\mathrm{PCl}$ ) specifically in recursive partitioning analysis (RPA) Group I, which is the most favorable group of LA-NSCLC patients.
\end{abstract}

Methods: Between March 2007 and February 2008, 62 patients in RPA group I were treated with sequential chemoradiotherapy and $\mathrm{PCl}$ for stage IIIB NSCLC. The induction chemotherapy consisted of 3 courses of cisplatin $\left(80 \mathrm{mg} / \mathrm{m}^{2}\right)$ and docetaxel $\left(80 \mathrm{mg} / \mathrm{m}^{2}\right)$; each course was given every $2 \mathrm{I}$ days. Thoracic radiotherapy (TRT) was given at a dose of $60 \mathrm{~Gy}$ using 3-D conformal planning. All patients received a total dose of $30 \mathrm{~Gy} \mathrm{PCl} \mathrm{(} 2 \mathrm{~Gy} / \mathrm{fr}, 5$ days a week), beginning on the first day of the TRT. Then, all patients received 3 further courses of the same chemotherapy protocol.

Results: Six (9.7\%) patients developed brain metastases during their clinical course. Only one (2\%) patient developed brain metastasis as the site of first treatment failure. Median brain metastasisfree survival, overall survival, and progression free survival were 16.6, 16.7, and 13.0 months, respectively. By univariate analysis, rates of BM were significantly higher in patients younger than 60 years of age $(p=0.03)$. Multivariate analysis showed no significant difference in BM-free survival according to gender, age, histology, and initial $\mathrm{T}$ - and $\mathrm{N}$-stage.

Conclusion: The current finding of almost equal bone metastasis free survival and overall survival in patients with LA-NSCLC in RPA group I suggests a longer survival for patients who receive PCl, and thereby have a reduced risk of BM.

\section{Background}

Brain metastases (BM) are a common complication of locally advanced non-small cell lung cancer (LA-NSCLC), especially in patients who undergo radical treatment pro- tocols. Of these patients, $21 \%$ to $54 \%$ develop BM during the course of their disease. [1-3]. and another 15-30\% carry a risk of the first treatment failure occurring in the brain. [4-7]. Studies have shown that the addition of 
chemotherapy to radiation therapy (RT) reduces extracranial distant metastases. [5]. and improves survival. [8,9]. but does not alter brain relapse rates. [5]. which emphasizes the need for treatment directed at BM micrometastases. In selected non-randomized $[1,4,10-12]$. and randomized studies. $[6,7,13,14]$. prophylactic cranial irradiation (PCI) has been demonstrated to reduce the incidence or delay the onset of BM in patients with LA-NSCLC after primary therapy.

Several factors including histology, stage, duration of survival, performance status, chemotherapy protocol, age at presentation, and sex have been associated with risk of BM development. [2,13,15-18]. In earlier studies, recursive partitioning analysis (RPA) classification was demonstrated to be a useful tool for predicting survival in patients with LA-NSCLC. $[19,20]$. Survival analysis revealed that RPA classification identified five distinct subgroups with significantly different median survival times, ranging from 2.9 mo in Group 5 to $16.2 \mathrm{mo}$ in Group 1. [20] (Table 1). In addition, longer survival of patients with LA-NSCLC treated with radiation alone or radiation plus chemotherapy was associated with an increased incidence of CNS metastases, according to a review of data from the Radiation Therapy Oncology Group (RTOG) studies. [1,2,19]. Based on these different analyses, it is reasonable to assume that many patients with LA-NSCLC do not live long enough to develop brain failure. We hypothesized that studies including patients with various RPA groups may not reflect the true value of PCI in specific groups; thus, with the current cohort we specifically evaluated the role of PCI in RPA Group 1 (Karnofsky performance status $\geq 90$ and previously treated by chemotherapy).

\section{Methods}

\section{Patients}

This retrospective analysis included 62 patients with a histological diagnosis of LA-NSCLC (stage IIIB) meeting the following criteria; age older than 18 and younger than 70 years, RPA Group 1 (Karnofsky Performance Status (KPS) $\geq 90$, previously treated by cisplatin-based chemotherapy), no superior sulcus tumor, no progressive disease fol- lowing induction chemotherapy, no prior history of thoracic and cranial RT, no more than $10 \%$ weight loss in the last 6 months, and signed written informed consent, those treated at our institution between March 2007 and February 2008. Further staging procedures included laboratory investigations, computed tomography of the thorax and abdomen, bone scintigraphy, pulmonary function tests, and baseline magnetic resonance imaging of the brain showing no suspicion for intracranial metastases. This study was formally approved by the Baskent University's institutional review board before collection of all patient information. Pretreatment patient and tumor characteristics are shown in Table 2.

\section{Chest Irradiation}

Three-dimensional conformal radiation therapy (3DCRT) was used in all patients. The treatment planning for eligible patients was based on gross tumor volume (GTV), which was restricted to all primary tumors and abnormally enlarged hilar or mediastinal lymph nodes greater than $1 \mathrm{~cm}$ in diameter seen on CT images or metabolically active areas on PET-CT. Clinical target volumes (CTVs) were defined by adding $1-\mathrm{cm}$ margins to GTVs. Planning target volume-1 (PTV1) was created by adding an addition $1.5 \mathrm{~cm}$ margin to CTVs, and PTV2 (boost field) was defined as the GTVs plus a 1.5-cm margin. Three-dimensional CRT was performed to minimize the volume of normal lung and surrounding normal tissues irradiated while providing coverage of PTVs by at least $95 \%$ isodose surfaces; the "100\% isodose" (prescription doses) were defined at each isocenter. Thoracic irradiation was given through the anteroposterior-posteroanterior (AP-PA) portals with individualized multileaf collimator blocks for PTV1 up to $46 \mathrm{~Gy}$, followed by off-spinal cord oblique portals up to 60 Gy (14 Gy boost) for PTV2, in a sequential manner. All patients received daily treatment five days a week, using 2 Gy fractions administered using linear accelerators with $6 \mathrm{MV}$ or $18 \mathrm{MV}$ photon energies (Clinac DBX-1031, and/or DHX-3323, Varian Medical Systems, Palo Alto, CA, USA). On the initial day of treatment and every week throughout the treatment, course field location was confirmed by comparing the digitally reconstructed radiographs and the portal images.

Table I: Radiation Therapy Oncology Group (RTOG) recursive partitioning analysis (RPA) groups in patients with locally-advanced non-small-cell lung cancer (LA-NSCLC).

\begin{tabular}{clr}
\hline RPA Group & Definition & Median survival (months) \\
\hline I & KPS of $>$ or $=90$, who received chemotherapy & 16.2 \\
II & KPS of $>$ or $=90$, who received no CT, but had no PE & 11.9 \\
III & KPS $<90$, younger than 70 years, with non-large cell histology & 9.6 \\
IV & KPS $>$ or $=90$, but with PE, or KPS $<90$, younger than 70 years, and with large cell histology, or & $5.6-6.4$ \\
V & older than 70 years, but without PE & \\
& older than 70, with PE & 2.9 \\
\hline
\end{tabular}

Abbreviations: KPS: Karnofsky Performance Status; CT: Chemotherapy; PE: Pleural effusion. 
Table 2: Patient and tumor characteristics.

\begin{tabular}{|c|c|}
\hline Characteristic & n (\%) \\
\hline \multicolumn{2}{|l|}{ Gender } \\
\hline Male & 48 (77.4) \\
\hline Female & $14(22.6)$ \\
\hline \multicolumn{2}{|l|}{ Age $(y)$} \\
\hline Median (range) & $59.6(38-69)$ \\
\hline$<60$ & $26(4 \mid .9)$ \\
\hline$\geq 60$ & $36(58.1)$ \\
\hline \multicolumn{2}{|l|}{ Histology } \\
\hline Epidermoid & $51(82.3)$ \\
\hline Adenocarcinoma & $11(17.7)$ \\
\hline \multicolumn{2}{|l|}{ T-stage } \\
\hline 1 & $0(0)$ \\
\hline 2 & $13(2 \mid .0)$ \\
\hline 3 & $12(19.3)$ \\
\hline 4 & 37 (59.7) \\
\hline \multicolumn{2}{|l|}{$\mathrm{N}$-stage } \\
\hline 0 & $4(6.5)$ \\
\hline I & $13(21.0)$ \\
\hline 2 & $19(30.6)$ \\
\hline 3 & $26(41.9)$ \\
\hline \multicolumn{2}{|l|}{ TN-stage } \\
\hline T4, NO & $4(6.5)$ \\
\hline $\mathrm{T} 4, \mathrm{NI}$ & $13(2 \mid .0)$ \\
\hline $\mathrm{T} 4, \mathrm{~N} 2$ & $18(29.0)$ \\
\hline T4, N3 & $3(4.8)$ \\
\hline T3, N3 & II (I7.7) \\
\hline $\mathrm{T} 2, \mathrm{~N} 3$ & $13(21.0)$ \\
\hline \multicolumn{2}{|c|}{ Response to induction CT } \\
\hline $\mathrm{CR}$ & II (I7.7) \\
\hline PR & $28(45.2)$ \\
\hline SD & $23(37.1)$ \\
\hline
\end{tabular}

Abbreviations: T: Tumor; N: Node; CT: Chemotherapy; CR: Complete response; PR: Partially response; SD: Stable disease.

\section{Prophylactic cranial irradiation}

Patients were simulated in a supine position with their heads fixed with thermoplastic head masks; radio-opaque markers were placed at the lateral orbital canthi to assist in blocking the lenses. The target volume consisted of all the intracranial contents with at least a $1-\mathrm{cm}$ margin around the bony skull at each margin. The inferior border at the cervical vertebral bodies was the $\mathrm{C} 1-\mathrm{C} 2$ interspace. Individually shaped radiation fields with multileaf collimators were used to define the irradiation target volume and exclude tissues that were not to be irradiated. Patients were treated on a megavoltage linear accelerator with 6 $\mathrm{MV}$ photons. All patients received PCI at 2 Gy per fraction, 5 days per week, for 3 weeks, with a total dose of $30 \mathrm{~Gy}$, beginning on the first day of the thoracic irradiation. Treatment was delivered with equally weighted right and left lateral fields with the dose calculated on the central ray at mid-separation of the beams.

\section{Chemotherapy}

All 62 patients received 3 courses of induction chemotherapy involving cisplatin $\left(80 \mathrm{mg} / \mathrm{m}^{2}\right)$ and docetaxel $(80$ $\mathrm{mg} / \mathrm{m}^{2}$ ) every 21 days, prior to RT. After completion of RT, all patients received 3 further courses of the same chemotherapy regimen. Chemotherapy was not permitted during the course of RT.

\section{Patient evaluation}

Patients were examined by a radiation oncologist once a week during the RT course. After completion of RT, patients were followed at bimonthly intervals or more frequently if necessary. Besides the standard work-up for locoregional and distant metastases, an MRI of the brain was performed at bimonthly intervals or more frequently if there was a suspicion of BM during the follow-up period.

\section{Statistics}

Variables analyzed were age at the time of diagnosis, gender, histological type (squamous cell carcinoma versus adenocarcinoma), and T-status (T1-2 versus 3-4), N-status (N0-1 versus 2-3). Univariate analyses were performed first for each variable to compare the $\mathrm{BM}+$ and $\mathrm{BM}$ - groups using a Chi-square test. The primary endpoint was BM-free survival (BMFS), calculated as the time between the first day of the PCI and the date of BM diagnosis. Similarly, overall survival (OS) was calculated as the time between the first day of the PCI and the date of death or last visit. Estimates of 1-year and 18-month survival were calculated by the Kaplan-Meier method, with comparisons between subsets performed with two-sided log-rank tests. All tests were two-tailed, with a p-value < 0.05 considered significant.

\section{Results}

At a median follow-up of 16.8 months (range: 7-18.6 months), 41 of the 62 patients with LA-NSCLC were alive at the time of analysis. Median survival for the entire population was 16.7 months (SE: 0.51; 95\% CI: 15.7-17.7 months). As illustrated in Figure 1, the 1-year, and 18month estimates of the OS were $86 \%$ and $62 \%$, respectively. Six patients $(9.7 \%)$ developed brain metastases at some time during the course of follow-up. Only one (2\%) patient developed brain metastasis as the site of first failure. The median time to the development of brain metastases was 7 months (range, 5-13 months). Brain metastasis was the only site of recurrence in one of six patients. Among the other five patients with brain metastasis, local progression, liver metastasis, and adrenal metastasis developed asynchronously in four, two, and one patient, respectively. Median BMFS was 16.7 months (SE:0.51, 95\% CI: 15.5-17.7 months). Two of the six patients with brain metastasis were alive at the time of analysis. As illustrated in Figure 1, BMFS rates at 1 year and 18 months were $92 \%$ and $90 \%$, respectively.

Sites of extracranial failure included liver in eight $(12.9 \%)$ patients, bone in five $(8.1 \%)$, lung in four $(6.5 \%)$, adrenal 


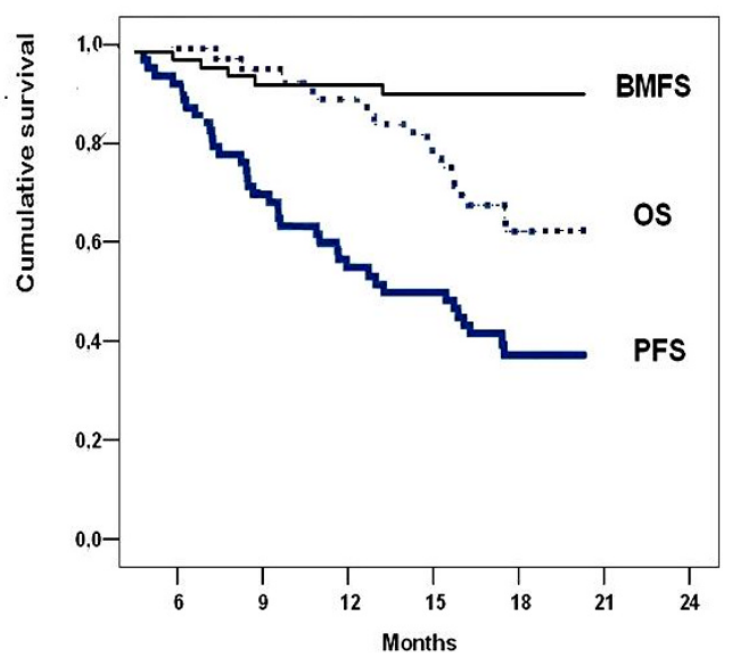

Figure I

Survival data of patients with locally advanced nonsmall cell lung cancer in recursive partitioning analysis group I treated with PCI. BMFS = Brain-metastasis free survival, OS = Overall survival, PFS = Progression free survival.

in three $(4.8 \%)$, and more than one site in two $(3.2 \%)$. A total of $23(37.1 \%)$ patients developed locoregional tumor progression during follow-up. Median progressionfree survival was 13.0 months (SE: 2.1 ; 95\% CI: 8.9-17.0) months. The estimates of 1-year and 18-month progression-free survival rates for the entire patient population were $54 \%$ and $37 \%$.

By univariate analysis, brain metastasis was significantly higher in patients with age $<60$ years $(p=0.03)$. An exploratory analysis of prognostic parameters using a Cox proportional hazards model showed no significant difference in BMFS according to gender, age, histology, and initial T- and N-stage ( $\mathrm{p}>0.05$ for all; Table 3 ).

\section{Discussion}

Several recent studies have reported excellent median and two-year survival rates of 15-25 months and 37-66\%, respectively, in patients with LA-NSCLC who receive multi-modal therapy. [1-5,19-25]. Incorporation of systemic chemotherapy was associated with a significant reduction in the incidence of extracranial metastases and longer survival; however this was also associated with increased rates of overall brain failure (21-54\%) and brain as the first site of relapse (15-30\%). [1-7,19,25]. These results emphasize the significance of treatment failure localized to the brain in patients with prolonged survival after aggressive treatment for LA-NSCLC. This finding has prompted the inclusion of PCI in some clinical studies. [1,4,10].

PCI, as administered in our protocol, demonstrated efficacy in reducing the incidence of overall $\mathrm{BM}$ and the brain as the first site of relapse ( $9.7 \%$ and $2 \%$, respectively). This is in accordance with the results of earlier randomized and non-randomized studies of combined therapies $[1,4,6,7,10-14]$. summarized in Table 4 . To our knowledge, the current study is the first attempt to specifically address the role of PCI in patients with LA-NSCLC in RPA Group 1. Despite the non-randomized nature and relatively short follow-up interval of our study, the BMFS and OS were almost equal, which suggests a longer survival for patients with LA-NSCLC who have a reduced BM risk from PCI protocols such as the one used here. In general, except for the study published by Pöttgen et al. [14]. in which only patients with stage IIIA NSCLC were studied, most studies included patients with disease in various stages and different histology, including adenosquamous and large cell tumors. In contrast, the current cohort included only patients with unresectable stage IIIB disease with epidermoid or adenocarcinoma histology.

A recent retrospective review of the Southwest Oncology Group (SWOG) database reported by Gaspar et al.[23]. included 422 patients with stage IIIA/IIIB: 268 (64\%) experienced disease progression; 54 (20\%) had progression in the brain only and $17(6.5 \%)$ in the brain and other sites simultaneously. Time from treatment to disease progression in the brain in 71 patients was as follows: during treatment, 16 relapses $(22.5 \%) ; 0$ to 16 weeks after treatment, 17 relapses $(24 \%) ; 16$ weeks to 6 months after treatment, 10 relapses $(14 \%) ; 6$ to 12 months after treatment, 16 relapses $(22.5 \%)$, and more than 12 months after treatment, 12 relapses (17\%). Thus, $83 \%$ of all brain relapses manifest in the first 12 months after treatment. Similarly, the median time to the development of brain metastases was 7 months (range, 5-13 months) in our study. Based on these results, although longer follow up is needed, we reasonably estimate that most of the brain relapses in our current cohort presented during the follow-up period, and potentially only a limited number of patients will subsequently be further affected; also, the majority of additional deaths will be associated with local progression and/or extracranial metastases, rather than brain failures.

In previously reported PCI studies, the tested total radiation dose and dose per fraction have been tested in previous studies and ranged from $20 \mathrm{~Gy}$ to $36 \mathrm{~Gy}$ and $2 \mathrm{~Gy}$ to 4 Gy, respectively. $[1,4,6,7,10-14]$. However, radiation regimens for PCI that have positively influenced patterns of CNS failures have included total doses of 30-36 Gy and fractional doses of 2-3 Gy. $[1,4,6,10,14]$. For the current 
Table 3: Multivariate analyses of predictive factors for brain metastases following prophylactic cranial irradiation in patients with locally advanced non-small cell lung cancer in recursive partitioning analysis group $I$.

\begin{tabular}{lcccc}
\hline Variable & Estimate (mo) & SE & $95 \% \mathrm{Cl}$ & $\mathrm{P}$-value \\
\hline Gender (female) & 15.7 & 0.56 & $14.6-16.8$ & 0.28 \\
Age (<60) & 15.0 & 0.62 & $13.8-16.2$ & 0.15 \\
Histology (epidermoid) & 16.6 & 0.58 & $15.4-17.7$ & 0.16 \\
T-stage (3-4) & 16.9 & 0.63 & $15.6-18.4$ & 0.92 \\
N-stage (2-3) & 16.2 & 0.65 & $15.0-17.5$ & 0.07
\end{tabular}

Abbreviations: T: Tumor; N: Node

study, we chose a smaller fractional dose of 2 Gy and a total dose of $30 \mathrm{~Gy}$ to minimize late tissue toxicity, as preferred in PCI protocols in small cell lung cancer (SCLC). In a previous study, Stuschke et al. [10]. demonstrated that this regimen effectively reduced BM from $54 \%$ to $13 \%$, with no differences in neuropsychologic testing in PCI versus non-PCI patients at 4 years. Furthermore, this $75 \%$ reduction in the rate of $\mathrm{BM}$ is thought to lead to an 8\% improvement in OS. [31]. Enlightened with the present evidence, it is reasonable to expect longer survival in patients with radically treated LA-NSCLC who recieve PCI. However, to achieve more firm conclusions, these estimates regarding the toxicity of PCI and its potential impact on survival need to be confirmed with larger randomized studies. One such study is the RTOG 0214 trial, which is a large-scale randomized phase III trial comparing PCI (2 Gy/fraction, totally 30 Gy in three weeks) versus observation in patients with LA-NSCLC following the completion of definitive locoregional/systemic therapy. It is aimed at evaluating whether or not PCI improves survival by safely decreasing the incidence of CNS metas- tases. The study was recently closed to accrual and the patients will be followed for two years in concert with the primary end-point.

Several factors have been associated with an increased risk of BM in both stage IIIA and IIIB NSCLC after combination therapies, including histology (epidermoid vs. nonepidermoid), gender (female vs. male), age at presentation (younger vs. older than 50 years), nodal status (pNo vs. residual nodal disease), performance score (KPS $\geq 70$ vs. $<70$ ), duration of survival (long vs. short), and chemotherapy protocol (taxane-platinum combination vs. other platinum-based combinations). [2,15-17,21,24]. In our cohort, it was not possible to test the predictive role of chemotherapy, large cell and adenosquamous histologies, and performance score due to the design of the treatment protocol, which was limited to patients classified by RPA groups. However, among the factors that could be analyzed, only age younger than 60 years was associated with higher risk of BM incidence following PCI. Additionally, there was a trend towards a higher risk of BM in patients with N2-3 stage compared to N0-1, but this difference did not reach statistical significance $(\mathrm{p}=0.07)$, which may be due to either the small size of the study population and/ or the short duration of the median follow-up interval. Despite of the inherent disadvantages, these findings appear to strongly well correlate with prior reports.

Grouping of patients according to RPA is an established method for prediction of survival in patients with LANSCLC. The role of RPA classification in predicting BM development in patients with NSCLC was studied by Komaki et al. [19]. by reviewing the data from four previously reported RTOG studies. Analysis showed that

Table 4: Studies of prophylactic cranial irradiation for patients with locally advanced non-small cell lung cancer in recursive partitioning analysis group $I$.

\begin{tabular}{|c|c|c|c|c|c|c|c|}
\hline Reference & $\mathrm{N}$ patients & Histology & Primary Tx & Dose of $\mathrm{PCl}$ & BM PCl- (\%) & $\mathrm{BM} \mathrm{PCl}+(\%)$ & P-value \\
\hline Albain et al. ${ }^{\prime}$ & 126 & All NSCLC & Trimodality & $36 \mathrm{~Gy}(2 \mathrm{~Gy} / \mathrm{fr})$ & 16 & 8 & 0.36 \\
\hline Strauss et al. ${ }^{4}$ & 54 & Non-squamous & Trimodality & 30 Gy (2 Gy/fr) & 12 & 0 & 0.32 \\
\hline Skarin et al. ${ }^{12}$ & 41 & All NSCLC & Trimodality & NS & 27 & 14 & \\
\hline Rusch et al. ${ }^{\prime \prime}$ & 75 & NS & Ctx + TRT & $\begin{array}{l}36 \text { Gy (2 Gy/fr) } \\
30 \text { Gy (3 Gy/fr) }\end{array}$ & - & 0 & - \\
\hline Stuschke et al. ${ }^{10}$ & 75 & All NSCLC & Trimodality & 30 Gy (2 Gy/fr) & 54 & 13 & 0.0004 \\
\hline Cox et al..$^{5}$ & 281 & All NSCLC & TRT & 20 Gy (2 Gy/fr) & 13 & 6 & 0.038 \\
\hline Unsawasdi. ${ }^{7}$ & 97 & All NSCLC & Trimodality Ctx+TRT & 30 Gy (3 Gy/fr) & 27 & 4 & 0.002 \\
\hline Russell et al. ${ }^{6}$ & 187 & Non-squamous & TRT & 30 Gy (3 Gy/fr) & 19 & 9 & 0.06 \\
\hline Mira et al. ${ }^{32}$ & 111 & All NSCLC & Ctx + TRT & $\begin{array}{c}30 \text { Gy }(2 \mathrm{~Gy} / \mathrm{fr}) \\
37.5 \mathrm{~Gy}(2.5 \mathrm{~Gy} / \mathrm{fr})\end{array}$ & 11 & 0 & 0.0001 \\
\hline Pöttgen et al. ${ }^{14}$ & 112 & All NSCLC (Stage IIIA) & Trimodality & 30 Gy (2 Gy/fr) & 27.2 & 9.1 & $\begin{array}{l}0.02 \\
0.04\end{array}$ \\
\hline Yavuz et al.* & 62 & $\begin{array}{c}\text { Squamous and adeno ca } \\
\text { (Stage IIIB) }\end{array}$ & $C t x+T R T$ & 30 Gy (2 Gy/fr) & - & 9.7 & - \\
\hline
\end{tabular}

(*) Current study.

Abbreviations: $\mathrm{Tx}=$ treatment; $\mathrm{NSCLC}=$ non-small cell lung cancer, $\mathrm{Ctx}=$ chemotherapy, $\mathrm{TRT}=$ thoracic radiotherapy; $\mathrm{PCl}=$ prophylactic cranial irradiation, $\mathrm{BM}=$ brain metastasis. 
patients included in RPA Groups 1 and 2 with the longest survival had the highest incidence of brain relapses $(18 \%$ vs. $9 \%, p=0.0004)$. To our knowledge, none of the previously reported PCI trials specifically studied a certain RPA group, and may have included patients belonging to different RPA groups. This raises the suspicion whether the BMFS might be underestimated by short OS due to deaths caused by extracranial metastases. Although our median follow-up was relatively short, the current finding of almost equal BMFS and OS (16.6 vs. 16.7, respectively) in RPA Group 1 patients lends further support to the expectation of a longer survival for patients with LA-NSCLC with reduced risk of $\mathrm{BM}$. We consider that our median survival data of 16.7 month is similar to RTOG studies which resulted of 16.2 months for RPA group 1 patients, [20]. and is at least similar to most of the recent chemoradiotherapy studies published for LA-NSCLC.[25].

One important limitation of our current study is the absence of the comparative neurocognitive assessments in pre- and post-PCI periods. In previous retrospective studies, controversial findings have been reported. [27-31]. In the meta-analysis of PCI in SCLC, [26]. two trials have evaluated the effect of PCI on neurocognitive functions. $[27,28]$. Arriagada et al.[32]. reported no significant differences in neurocognitive function between patients receiving PCI (24 Gy in 8 fractions) and those in the observation group. Gregor et al. [31]. randomized patients to PCI or no PCI. They reported that there was an impairment of cognitive function and QOL before PCI, and further impairment at 6 and 12 months in both groups. No additional impairment was associated with PCI. None of other randomized trials using PCI, except for the recent German trial, [14]. collected detailed prospective data on the long-term effects of PCI on neurocognitive function in patients with NSCLC. An important limitation of the German trial was the absence of baseline neurocognitive testing. Nevertheless, no significant differences were detected in the patient cohort receiving PCI in comparison with those without PCI despite a detailed neurocognitive investigation in long-term survivors, more than 4 years after treatment. Based on the current evidence from SCLC and NSCLC studies, it is reasonable to assume that PCI regimens consisting of 20-30 Gy given in 2-3 Gy per fractions, as used in the current cohort, will produce little toxicity on brain tissue for the first 1 to 2 years after PCI. However, further studies with longer follow-up and sequential pre- and post-PCI evaluations are needed to fully assess late toxicity of PCI on brain tissue. One hopes that the recent RTOG 0214 protocol will resolve many unanswered issues, including the possible changes in neurocognitive function following PCI.

\section{Conclusion}

PCI as administered in our protocol demonstrated efficacy in reducing the overall incidence of $\mathrm{BM}$ and the rate at which the brain is the first site of relapse; our findings also suggest a longer survival for selected patients with LANSCLC. We believe that it is necessary to research the role of PCI in RPA group 1 patients with LA-NSCLC in randomized clinical trials with larger patient populations; such studies may provide further data that may help select patients who are most likely to benefit from PCI.

\section{Competing interests}

The authors declare that they have no competing interests.

\section{Authors' contributions}

AAY conceived of the study and wrote the manuscript. ET collected the samples and patient's clinical data. CO and MNY participated in the design of the study and helped write the paper.

All authors read and approved the final manuscript.

\section{Acknowledgements}

Results of this study have been presented at $7^{\text {th }}$ Congress of Balkan Union of Oncology, 15-19 October 2008, Kusadasi, Turkey.

\section{References}

I. Albain KS, Rusch VW, Crowley JJ, Rice TW, Turrisi AT 3rd, Weick JK, Lonchyna VA, Presant CA, McKenna RJ, Gandara DR: Concurrent cisplatin/etoposide plus chest radiotherapy followed by surgery for stages IIIA (N2) and IIIB non-small-cell lung cancer: mature results of Southwest Oncology Group phase II study 8805. J Clin Oncol 1995, 13:1880-1892.

2. Andre F, Grunenwald D, Pujol JL, Girard P, Dujon A, Brouchet L, Brichon PY, Westeel V, Le Chevalier T: Patterns of relapse of N2 nonsmall-cell lung carcinoma patients treated with preoperative chemotherapy: should prophylactic cranial irradiation be reconsidered? Cancer 200I, 9 I:2394-2400.

3. Chen AM, Jahan TM, Jablons DM, Garcia J, Larson DA: Risk of cerebral metastases and neurological death after pathological complete response to neoadjuvant therapy for locally advanced nonsmall-cell lung cancer: clinical implications for the subsequent management of the brain. Cancer 2007, I5, I 09: I668-1675.

4. Strauss GM, Herndon JE, Sherman DD, Mathisen DJ, Carey RW, Choi NC, Rege VB, Modeas C, Green MR: Neoadjuvant chemotherapy and radiotherapy followed by surgery in stage IIIA non-small cell carcinoma of the lung: Report of a Cancer and Leukemia Group B phase II study. J Clin Oncol 1992, 10:1237-1244.

5. Cox JD, Scott CB, Byhardt RW, Emami B, Russell AH, Fu KK, Parliament MB, Komaki R, Gaspar LE: Addition of chemotherapy to radiation therapy alters failure patterns by cell type within non-small cell carcinoma of lung (NSCCL): Analysis of Radiation Therapy Oncology Group (RTOG) trials. Int J Radiat Oncol Biol Phys 1999, 43(3):505-509.

6. Russell AH, Pajak TE, Selim HM, Paradelo JC, Murray K, Bansal P, Cooper JD, Silverman S, Clement JA: Prophylactic cranial irradiation for lung cancer patients at high risk for development of cerebral metastasis: Results of a prospective randomized trial conducted by the Radiation Therapy Oncology Group. Int J Radiat Oncol Biol Phys I99I, 2 I (3):637-643.

7. Umsawasdi T, Valdivieso M, Chen TT, Barkley HT Jr, Booser DJ, Chiuten DF, Dhingra HM, Murphy WK, Dixon CL, Farha P: Role of elective brain irradiation during combined chemoradiotherapy for limited disease non-small cell lung cancer. J NeuroOncol 1984, 2:253-259.

8. Sause WT, Scott C, Taylor S, Johnson D, Livingston R, Komaki R, Emami B, Curran WJ, Byhardt RW, Turrisi AT: Radiation Therapy Oncology Group (RTOG) 88-08 and Eastern Cooperative Oncology Group (ECOG) 4588: Preliminary results of a phase III trial in regionally advanced, unresectable nonsmallcell lung cancer. J Natl Cancer Inst 1995, 87(3): I98-205. 
9. Dillman RO, Herndon J, Seagren SL, Eaton WL Jr, Green MR: Improved survival in stage III non-small-cell lung cancer: Seven-year follow-up of Cancer and Leukemia Group B (CALGB) 8433 trial. J Natl Cancer Inst 1996, 88( I7):|2 |0-I2I5.

10. Stuschke M, Eberhardt W, Pöttgen C, Stamatis G, Wilke H, Stüben G, Stöblen F, Wilhelm HH, Menker H, Teschler H, Müller RD, Budach V, Seeber S, Sack H: Prophylactic cranial irradiation in locally advanced non-small-cell lung cancer after multimodality treatment: long-term follow-up and investigations of late neuropsychologic effects. J Clin Oncol 1999, 17:2700-2709.

II. Rusch VW, Griffin BR, Livingston RB: The role of prophylactic cranial irradiation in regionally advanced non-small cell lung cancer. A Southwest Oncology Group Study. J Thorac Cardiovasc Surg 1989, 98(4):535-539.

12. Skarin A, Jochelson M, Sheldon T, Malcolm A, Oliynyk P, Overholt R, Hunt $M$, Frei E 3rd: Neoadjuvant chemotherapy in marginally resectable stage III MO non-small cell lung cancer: Longterm follow-up in 4I patients. J Surg Oncol 1989, 40(4):266-274.

13. Cox JD, Stanley K, Petrovich Z, Paig C, Yesner R: Cranial irradiation in cancer of the lung of all cell types. JAMA I98I, 245:469-472.

14. Pöttgen C, Eberhardt W, Grannass A, Korfee S, Stüben G, Teschler $H$, Stamatis G, Wagner H, Passlick B, Petersen V, Budach V, Wilhelm $H$, Wanke I, Hirche H, Wilke HJ, Stuschke M: Prophylactic cranial irradiation in operable stage IIIA non-small-cell lung cancer treated with neoadjuvant chemoradiotherapy: Results from a Geman multicenter trial. J Clin Oncol 2007, 25:4987-4992.

15. Robnett TJ, Machtay M, Stevenson JP, Algazy KM, Hahn SM: Factors affecting the risk of brain metastases after definitive chemoradiation for locally advanced non-small-cell lung carcinoma. I Clin Oncol 200I, I 9:1344-1349.

16. Law A, Karp DD, Dipetrillo T, Daly BT: Emergence of increased cerebral metastasis after high-dose preoperative radiotherapy with chemotherapy in patients with locally advanced non-small cell lung carcinoma. Cancer 200I, 92:160-164.

17. Ceresoli GL, Reni M, Chiesa G, Carretta A, Schipani S, Passoni P, Bolognesi A, Zannini P, Villa E: Brain metastases in locally advanced nonsmall cell lung carcinoma after multimodality treatment: risk factors analysis. Cancer 2002, 95:605-6/2

18. Carolan H, Sun AY, Bezjak A, Yi QL, Payne D, Kane G, Waldron J, Leighl N, Feld R, Burkes R, Keshavjee S, Shepherd F: Does the incidence and outcome of brain metastases in locally advanced non-small cell lung cancer justify prophylactic cranial irradiation or early detection? Lung Cancer 2005, 49:109-115.

19. Komaki R, Scott CB, Byhardt R, Emami B, Asbell SO, Russell $A H$, Roach M, Parliament MB, Gaspar LE: Failure patterns by prognostic group determined by recursive partitioning analysis (RPA) of I 547 patients on four Radiation Therapy Oncology Group (RTOG) studies in inoperable non-small-cell lung cancer. Int I Radiat Oncol Biol Phys 1998, 42(2):263-267.

20. Werner-Wasik M, Scott C, Cox JD, Sause WT, Byhardt RW, Asbell $S$, Russell A, Komaki R, Lee JS: Recursive partitioning analysis of 1999 Radiation Therapy Oncology Group (RTOG) patients with locally-advanced non-small-cell lung cancer (LANSCLC): identification of five groups with different survival. Int J Radiat Oncol Biol Phys 2000, 48: I475-1482.

21. Choi NC, Carey RW, Daly W, Mathisen D, Wain J, Wright C, Lynch $T$, Grossbard M, Grillo $H$ : Potential impact on survival of improved tumor downstaging and resection rate by preoperative twice-daily radiation and concurrent chemotherapy in stage IIIA non-smallcell lung cancer. J Clin Oncol 1997, 15:71 2-722.

22. Eberhardt W, Wilke H, Stamatis G, Stuschke M, Harstrick A, Menker $H$, Krause B, Müeller MR, Stahl M, Flasshove M, Budach V, Greschuchna D, Konietzko N, Sack H, Seeber S: Preoperative chemotherapy followed by concurrent chemoradiation therapy based on hyperfractionated accelerated radiation therapy and definitive surgery in locally advanced non-small-cell lung cancer: Mature results of a phase II trial. J Clin Oncol 1998, 16:622-634.

23. Gaspar LE, Chansky K, Albain KS, Vallieres E, Rusch V, Crowley JJ, Livingston RB, Gandara DR: Time from treatment to subsequent diagnosis of brain metastasis in stage III non-small-cell lung cancer. A retrospective review by the Southwest Oncology Group. J Clin Oncol 2005, 23:2955-296I.
24. Mamon HJ, Yeap BY, Jänne PA, Reblando J, Shrager S, Jaklitsch MT, Mentzer S, Lukanich JM, Sugarbaker DJ, Baldini EH, Berman S, Skarin $A$, Bueno R: High risk of brain metastases in surgically staged IIIA non-small-cell lung cancer patients treated with surgery, chemotherapy, and radiation. J Clin Oncol 2005, 23:1530-1537.

25. Blackstock AW, Govindan R: Definitive chemoradiation for the treatment of locally advanced non small-cell lung cancer. J Clin Oncol 2007, 25:4|46-4I52.

26. Auperin A, Arriagada R, Pignon JP, Le Pechoux C, Gregor A, Stephens $\mathrm{RJ}$ : Prophylactic cranial irradiation for patients with smallcell lung cancer in complete remission. NEJM 1999, 34I(7):476-484.

27. Cull A, Gregor A, Hopwood P, Macbeth F, Karnicka-Mlodkowska H, Thatcher N, Burt P, Stout R, Stepniewska K, Stewart M: Neurological and cognitive impairment in long-term survivors of small cell lung cancer. Eur J Cancer 1994, 30: 1067- 1064.

28. Johnson BE, Becker B, Goff WB 2nd, Petronas N, Krehbiel MA, Makuch RW, McKenna G, Glatstein E, Ihde DC: Neurologic, neuropsychologic, and computed cranial tomography scan abnormalities in 2- to 10-year survivors of small-cell lung cancer. J Clin Oncol 1985, 3:1659-1667.

29. Johnson BE, Patronas N, Hayes W, Grayson J, Becker B, Gnepp D, Rowland J, Anderson A, Glatstein E, Ihde DC: Neurologic, computed cranial tomographic, and magnetic resonance imaging abnormalities in patients with small-cell lung cancer: further follow-up of 6- to I3-year survivors. I Clin Oncol 1990, 8:48-56.

30. van Oosterhout AG, Pol M van de, ten Velde GP, Twijnstra A: Neurologic disorders in $\mathbf{2 0 3}$ consecutive patients with small cell lung cancer. Results of a longitudinal study. Cancer 1996, 77: $|434-| 44 \mid$.

31. Gregor A, Cull A, Stephens RJ, Kirkpatrick JA, Yarnold JR, Girling DJ, Macbeth FR, Stout R, Machin D: Prophylactic cranial irradiation is indicated following complete response to induction therapy in small cell lung cancer: results of a multicentre randomised trial. United Kingdom Coordinating Committee for Cancer Research (UKCCCR) and the European Organization for Research and Treatment of Cancer (EORTC). Eur J Cancer 1997, 33: 1752-1758.

32. Arriagada R, Le Chevalier T, Rivière A, Chomy P, Monnet I, Bardet E, Santos-Miranda JA, Le Péhoux C, Tarayre M, Benhamou S, Laplanche $A$ : Patterns of failure after prophylactic cranial irradiation in small-cell lung cancer: analysis of $\mathbf{5 0 5}$ randomized patients. Ann Oncol 2002, 13:748-754.

33. Mira JG, Taylor SL, Stephens RL, Chen T: Simultaneous chemotherapy-radiotherapy with prophylactic cranial irradiation for inoperable adeno and large cell lung carcinoma: a Southwest Oncology Group Study. Int J Radiat Oncol Biol Phys 1988, | 5(3):757-76I.

Publish with BioMed Central and every scientist can read your work free of charge

"BioMed Central will be the most significant development for disseminating the results of biomedical research in our lifetime. "

Sir Paul Nurse, Cancer Research UK

Your research papers will be:

- available free of charge to the entire biomedical community

- peer reviewed and published immediately upon acceptance

- cited in PubMed and archived on PubMed Central

- yours - you keep the copyright
BioMedcentral 